\title{
"The Dying Swan" by A. Pavlova: Choreography and Iconography of the Image
}

\section{Tatiana Portnova ${ }^{\dagger}$}

\section{Abstract}

In the article, an approach to the analysis of the artwork that represented the image of the great ballerina, A. Pavlova in the choreographic miniature The Dying Swan was implemented for the first time. The article contains the solution of the problem of understanding and comprehension of all artistic components of visual characteristics of the created works, which can be used in reconstructions and modern interpretations of a choreographic performance. The main iconographic motives of The Dying Swan by different artists have been illustrated on the materials of fine art, and their comparative analysis has been given.

The author aims at tracing the way the idea and mechanisms of interpretation of A. Pavlova's role are transformed into the structure of a still image. Based on the definitions considered, specific author's solutions are analysed, and their ideological-artistic originality (features of composition construction, mise en scene lighting plot of the performance, acting nuances) is revealed about the stage representation and perception of classical choreography. In the article, a significant place is given to the work of sculpture created by A. Pavlova on a topic of The Dying Swan, which has been scarcely examined, in which the specificity of the ballerina's performing art has been interpreted as a secondary relatively independent actor's activity and her creativity has been revealed in the format of the figurative interpretation as the individual performing interpretation of a stage of primary (author's) scenic activities. The article concludes that the presented sculptural-plastic interpretation of A. Pavlova's dance as a performer of the act is further superimposed on the interpretation of the choreographic image and manifested in the expressiveness of the movements set by the ballet-master, resulting in a new semantic variant based on the previous one.

Keywords: A. Pavlova; The Dying Swan, The Iconography of the image, Compositional Scheme, Choreography of the Role, Artistic Interpretation

\footnotetext{
${ }^{\dagger}$ Russian State University named after A.N. Kosygin, Email: t.portnova@yahoo.com (C) 2019 Portnova. This is an Open Access article distributed under the terms of the Creative Commons Attribution License (http://creativecommons.org/licenses/by/2.0), which permits unrestricted use, distribution, and reproduction in any medium, provided the original work is properly cited.
} 


\section{Introduction}

Many chapters, both in domestic and foreign art criticism, are dedicated to Russian ballet as a holistic phenomenon, that is, as a theatricalscenic, choreographic, aesthetic-philosophical, and culturological phenomenon. A. Pavlova's creativity constantly attracts the attention of researchers, "...New generations of people discover with astonishment the true meaning of a set of ideas and values of creativity, destiny and personality of Anna Pavlova" (1881-1931), one of the leading representatives of Russian ballet in the early twentieth century. When examining the ballerina's artistic heritage, Russian and foreign researchers aim to actualise its content, discover new facts, disclose littleknown hypostases of her personality and destiny, and reveal a 'dialogue' with the present" (Smirnova, 2004:11; McLean, 2008; Fisher, 2012; Edward, 2018). Indeed, Pavlova's creativity and its display in related arts have not yet been comprehended in various aspects. This issue arose only as a result of stating the indisputable facts of the history of the ballet theater and has not been separately described in detail. Our research task is to study the specificity of classical dance as a phenomenon, primarily as an expressive-depictive one, proceeding from the fact that ballet, like no other genre of theatrical art, has left amazing creativity samples, sometimes extremely contrasting in artistic terms, in the heritage of the nineteenth and early twentieth centuries. The main direction of the iconographic research is associated with ballet art, and this is not accidental, because this art is characterised by conventionality and canonicity. Focusing on one role performed by $A$. Pavlova, which is based on the stylistic principle and contains the moments of similarity and repeatability, we initially focus on a certain set of tools after having clearly defined a range of scientific interests. The iconographic method, which is directly related to the interpretation of those works, combining symbolic and naturalistic elements, mainly refers to the image of the swan performed by A. Pavlova that became a symbol of Russian ballet, and an iconographic scheme of its representation was formed in the visualisation of this image.

The research purpose is to trace and scientifically comprehend the iconography of The Dying Swan performed by A. Pavlova in the works of fine art of the late nineteenth-early twentieth centuries, at the time when the dancer lived and worked; to identify in the comparative analysis the artistic features and interpretation of the artistic image of the swan in creative works of a number of masters in the context of the stated topic.

The research objectives are as follows:

- to present examples of the interpretation of the image of The Dying Swan in the history of the artistic culture of the late nineteenth - early twentieth centuries;

- to substantiate the basic tendencies of the formation of the iconography of the image of the swan in visual art in the context of the choreographic stage direction of the act;

- to formulate the author's model of the historically established system of the artistic vision by each considered artist;

- to analyse the compositional features of the developed iconographic schemes and reveal the nature of the influence of the director's staging ideas on the stylistic visualisation in the aspect of interrelations of ballet and plastic arts;

- to trace changes in the nature of the tasks, set by A. Pavlova, in creating the sculptural image of the swan that is necessary for the process of creating a stage image.

\section{Methods}

The source of research is the Russian ballet theatre of the late nineteenth-early twentieth centuries, represented by the names of outstanding ballet masters and ballet dancers, among whom the personality of A. Pavlova and her ballet roles are of particular importance. In the extensive scientific literature on ballet in Russian and foreign languages, priority is given to the study of A. Pavlova's recognised dance 
creativity, including the stage destiny of her famous act, The Dying Swan, composed especially for her by a choreographer M. Fokine (1961; 1981). Both contemporaries (Granenbeiy, 1927; Kranss, 1931; Hyden, 1932) and the authors of later generations (Kerensky, 1973; Money, 1982) are among the researchers of $A$. Pavlova's creativity. A. Pavlova's husband and impresario $V$. Dandre, who wrote the only remembrance book recognised both in our country and abroad, can be mentioned due to the traditional descriptions of A. Pavlova's choreographic art (Dandre, 2003). However, this book did not provide any information on the substance of the topic indicated. Contemporary theatre studies have access both to handwritten and graphics archive materials, which make it possible to see Russian ballet more clearly as a visual phenomenon and to use the interdisciplinary research methods in its study (Neishtadt, 1950). The available iconographic sources concerning the image of A. Pavlova's The Dying Swan reveal new boundaries of the formation and development of typical features of the choreographic miniature as a special theatrical genre (Materials about A. Pavlova). These are two-dimensional graphic sheets and paintings, three-dimensional sculptural works, in the creation of which well-known and littleknown artists participated (Catalogue of the Commemorative Exhibition, 1956; also Figure 1).

\section{Figure 1. A. Pavlova - "The Dying Swan". Bronze. Private Collection. Catalogue of the Commemorative Exhibition organised by the London Museum. London, 1956.}

They fixed A. Pavlova's image in this act. Their works reflect the results of the artistic process, the birth and the ways of creating a staging idea, enriching $M$. Fokine's stage concept and A. Pavlova's performance concept with the author's artistic solution. In this regard, the activity of such masters as B. Anisfeld, I. Bilibin, G. Lavrov, S. Sudbinin and others has not been properly studied by scientists and needs a special analysis.

The object of analysis are also photos that describe and visualise the A. Pavlova's dance. These are museum exhibits and photodocumentary materials from the State Tretyakov Gallery, A. Bakhrushin State Central Theatre Museum (Moscow), and the London National Museum.

The use of various sources and research literature, in combination with other materials, allowed the authour to systematise the available data, conduct the corresponding analysis, and solve a number of problems of iconography with regard to choreography. Various written sources containing the description of A. Pavlova's dance (both published and archival sources), museum exhibits and materials (photo documents, video recordings) have been used in preparing the article.

Historical-culturological, contextual, and typological methods of the work with the material and the method of theatrical-art analysis of the works of art have been used in the research.

- The author used the historicalculturological method for considering the role of The Dying Swan as a cultural phenomenon that appeared in the late nineteenth-early twentieth centuries and had a significant impact on the 
creativity of artists at the turn of the centuries;

- the contextual method determined the author's view of the study of artworks that captured an image of A. Pavlova's swan in interaction with the choreographic drama and staging principles of the famous miniature;

- the theatrical-art method allowed to identify and substantiate the main trends of the embodiment of the choreographic image in fine arts of the late nineteenth early twentieth centuries;

- the typological method made it possible to consider sustainable iconographic schemes in the pictures of A. Pavlova in the image of the swan and to analyse the nuances of its interpretations by various masters depending on the author's vision, the stylistics of the solution and the choice of technical means.

The study of the thinking process and the course of rehearsal work, the description of the creative atmosphere in the act staging, as well as the experience of the artist's friendship with the director and artists were essential for studying the process of the formation of the plastic image of the Swan created both by A. Pavlova and some sculptors. The correlation of the choreographic source and the artistic result obtained in the material proves to be important for understanding the integrative links in the creative process of the creation of a synthetic artistic image.

\section{The Results}

\section{Pavlova - The Dying Swan by B. Anisfeld and I. Bilibin}

Only two masters of the creative association "World of Art" will be considered in the article, namely the works of B. Anisfeld, A. Pavlova. The Dying Swan (1930) and I. Bilibin, A. Pavlova - The Dying Swan (1923). These masters choose one and the same motive of The Dying Swan created by $M$. Fokine for the music of K. Saint-Saens and performed on stage by A. Pavlova. It should be noted that this is a special topic in ballet iconography about A. Pavlova, which helped many Russian and foreign artists of that time to create her image. This is a well-known fact that this act produced a significant resonance, went around the whole globe with triumph and captured spectators of many countries with its truthfulness and depth." The Dying Swan was the best act of the evening performance ... the whole miniature on pointe shoes, by its amazing expressiveness of plastic speech, by fine artistry, a mournful image exhausting the poetic program of the title to the end is created by relatively insignificant means" (Cherepnin, 1914b). S. Lifar wrote about his first impression of the contemplation of A. Pavlova's dance: "When Anna Pavlova appeared on stage, it seemed to me that I had never seen anything that would be compared with Anna Pavlova's superhuman, divine beauty and lightness, absolutely weightless airiness and grace. From the first minute I was amazed and enchanted by the simplicity, lightness of her plastics: no fouettes, no virtuoso tricks - only beauty and only airy slide - as light as if she does not need to make any more effort, as if she had a divine, Mozartian gift and added nothing to this lightest and wonderful gift. I saw Anna Pavlova as a genius, not a dancer, I bowed down before this divine genius and could not reason for the first minutes, I could not, did not dare to see any flaws, any shortcomings - I saw the revelation of heaven and was not on earth ..." (Nadezhdin, 2010). When considering the two images of $A$. Pavlova, created by I. Bilibin and B. Anisfeld, their difference, not their similarity, becomes evident. As for the two-minute act staged by M. Fokine, the artists focus on different, diametrically opposite moments for the visual imprint. I. Bilibin chooses the initial moment of the dance when A. Pavlova stands on her toes and floats quietly along the stage, while B. Anisfeld chooses the final moment when the dancer's hands pressed to the ground are perceived as the last call of life. The depth of the image is the main difference between these works. I. Bilibin's work is aimed at expressing only graceful and dreamy plastic of a bird, without deeply penetrating the psychology of the image. In I. Bilibin's work, a graphic origin is prevailing; he carefully studies the swan costume, the image seems earthbound. In 
addition to the unique decorativeness peculiar to the artist's style, associated with the motives of folk creativity, he captured quite precisely the movement of hands and feet, the dance of the whole body of the ballerina. The expressive line outlining the dancer's figure gives rise to something fragile and simultaneously attractively earthly.

In contrast to I. Bilibin, Anisfeld stressed the unsteady plasticity, the psychological breakdown of the image. The actress of the performance is simultaneously an actress of emotional experience. For this reason, a sense of the mysterious uncertainty, the elusiveness of her "creative formula" is further enhanced. This work was written by B. Anisfeld in 1930, preceding the next, fatal year, when A. Pavlova passed away. The artist regards a well-known role as his true drama, raises it to the level of a symbol. At the same time, vague, but strongly and existing presentiments are expressed here; they were very illustrative for the time at the turn of the century.

Considering the work of $\mathrm{B}$. Anisfeld, there is an involuntary desire to draw a parallel between this work and M. Vrubel's painting The Swan Princess (1900, State Stage costume), which are similar because the image is comprehended through romantic thinking (see, Figures 2 and 3 ).

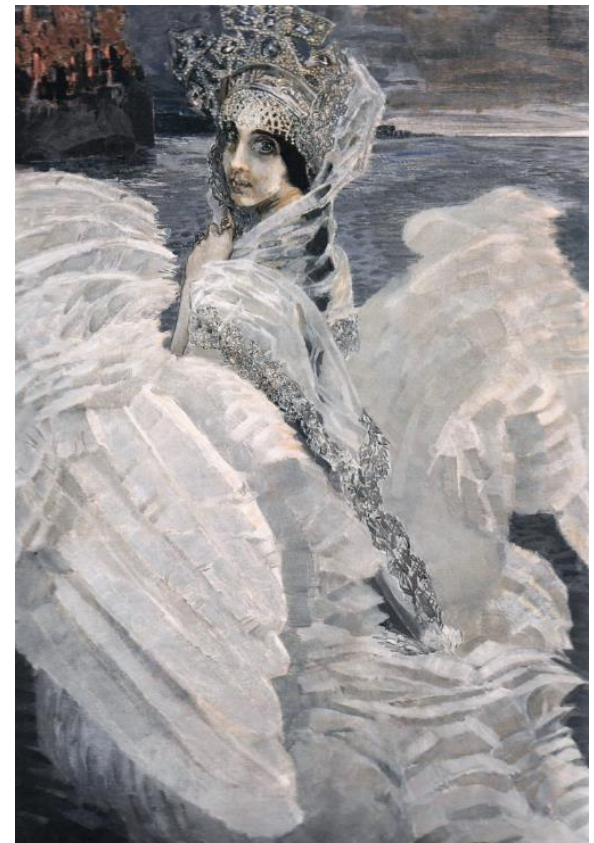

Figure 2: M. Vrubel. The Swan Princess. 1900. Oil on canvas.

Source: The State Tretyakov Gallery, Moscow.

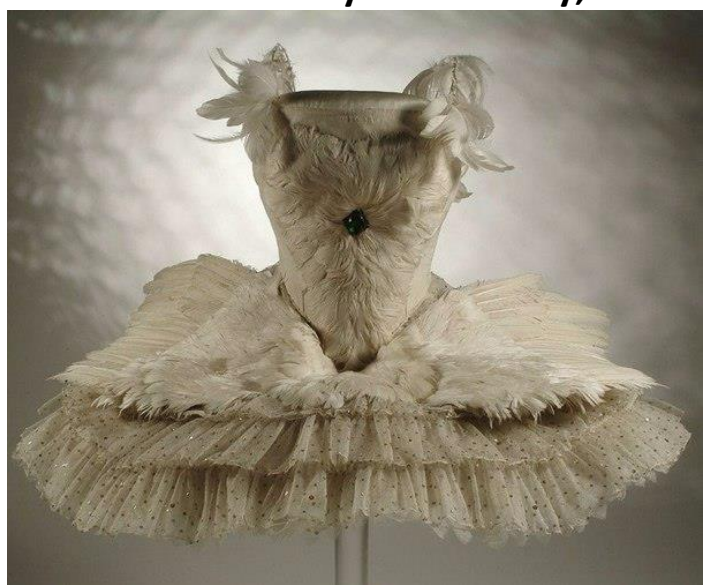

Figure 3. Stage costume of A. Pavlova performing "The Dying Swan". Source: Museum of National Opera, Paris 
Placing The Dying Swan in the obscure, dark, exciting landscape, B. Anisfeld thereby achieves a mood of tragedy, which characterises the last seconds of the dance. Depicting The Swan Princess among the wide dark expanse of the sea, where the noisy splash of her wings seems to be heard, M. Vrubel also adds a sense of mystery and anxiety to the image, creates a fine counterpoint of the image. The artist regards nature as a focus, as a certain point in the space of the universe, where its embodiment is possible. This is the whole world narrowed to the concepts of the human and, at the same time, a man extended to the concept of the all-natural.

Vrubel's The Swan Princess is similar not so much to The Dying Swan of M. Fokine as to Odette - a bird-girl from P. Tchaikovsky's ballet the Swan Lake. To be exact, this is a reference to its fourth act, when in the gloomy worrying night on the shore of the Swan Lake she yearns, shocked by the betrayal of the prince. Vrubel's The Swan Princess, like the ballet heroine, expresses a human quality - offense. Her hope of rescue is lost; she passionately waits for the rescuer, but she is too proud to beg for rescue. Thus, the content of Vrubel's image is based on loyalty. Romanticism as an era in European culture, on the one hand, and Romanticism as a world view, on the other hand, proved to be so important in the artistic life of the studied time that, as the search range naturally narrows down, it was logical to focus on stylisation, as it was understood within Romanticism. The romantic world view, within which stylisation was a natural attitude to unfamiliar, exotic cultures, was peculiar to many artists (in the broadest sense of the word) of the Silver Age. At the same time, Romanticism with all its variety of motives and images, stylistic nuances and branches, often served as an object of stylisation.

B. Anisfeld's The Dying Swan is primarily a bird; it has a natural origin. Outlining the elegantly elongated figure of A. Pavlova, a swan, with smooth, soft rounded lines, depicting a white ballet skirt with wavy strokes, B. Anisfeld, not considering it necessary to scrupulously draw his heroine, strives to ensure that the image would not be accurately outlined, it should only be guessed. The artist exaggerates it in part; A. Pavlova's small head with indistinct facial features is rather a head of a bird, not of a woman. No wonder the artist uses a symbol in the landscape - a bird flying in the sky, rushing somewhere beyond the sheet; once again it reminds us of deep closeness and trueness of the swan image created by the ballerina.

Thus, in the works of I. Bilibin and B. Anisfeld, the features of a new aspect of the ballet theme are observed: a desire to express a ballet image, to capture a particular actor in the role he/she created. Such an aspect of artistic thinking will be further fully developed and become one of the main aspects of the creativity of many artists.

It should be noted that this is a special theme in ballet iconography of the ballerina, who was depicted by many both Russian and foreign artists of that time (G. Lavrov, N. Danko, J. Lavery, A. Grupenberg, E. Oppler, A. Kainer and others).

\section{Anna Pavlova - The Swan by G. Lavrov and S. Sudbinin}

The same motive of The Dying Swan was used in sculpture in portraits by $G$. Lavrov and $S$. Sudbinin - G.D. Lavrov Anna Pavlova - The Swan (1930, foreign collection), S.N. Sudbinin - Anna Pavlova - The Swan (State Central Theatre Museum named after A. Bakhrushin), complementing the idea of one of the best roles of the ballerina. The comparison of the sculptural works of two masters shows that the artists interpret the same motives differently. S. Sudbinin has the opportunity to partially monumentalise A. Pavlova's image and strives for the maximum concentration of the image, while G. Lavrov is a gifted lyric poet; he adds fine poetry to the same motive and partly idealises it. Fine calm modelling of the face and its lyrical interpretation have much in common with 0 . Rodin's images made in marble, with the radiant surface permeated with light, where techniques of the contrast of the worked and unworked stone are used. The ballerina's image is similar to O. Rodin's images not only stylistically, but also in the expression of fine nuances of human emotions. It attracts with a state of dreaminess, careful listening, the combination of fragile grace 
and spiritual movement. A. Pavlova - The Swan by $\mathrm{G}$. Lavrov represents the life during the dance, while A. Pavlova - The Swan by S. Sudbinin is the embodiment of the mental torment of the last dying moments of the Swan. Sudbinin gives only the very essence of the role, as a certain ultimate concentrate, a clot of feeling, psychological agitation passing into calmness, harmonious clarity. The words of Y. Sobolev perfectly expresses the emotional mood of Pavlova's image by Sudbinin: "...in this lyrical drama, in the drama of breakdown and death of a tender, beautiful bird with purely white weak wings, there is the whole gamut of the suffering heart... The feminine swan played by Pavlova dies calmly. Just like sunset rays fade away, quietly immersing into the evening lake" (Sobolev, 1914: 9-10). The sculptor, like an archaeologist, carefully removes the outer cover layer after layer, behind which the human soul is found (see, Figure 4).

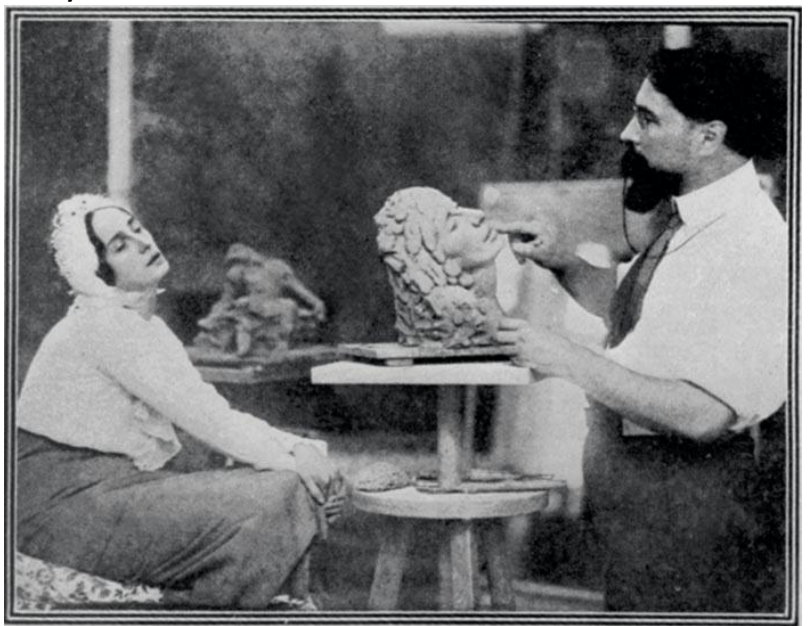

Figure 4: A. Pavlova as "The Swan" and Sculptor S. Sudbinin, A photo-Bronze Sculpture of 1905, Source: Located in A.A. Bakhrushin State Central Theater Museum, Moscow

Thus, noting the individuality of the images created by I. Bilibin, B. Anisfeld, G. Lavrov and S. Sudbinin, we can see a single ideological and philosophical concept in them - A. Pavlova's romantic roles embodied in the unforgettable choreographic miniature. All these works are distinguished by the similar canonical genre structure. The actor's personality is comprehended not only through the image (figures, poses, portrait features, costume), but also through psychological intonations (temper, state of mind, world perception).

Another group of works connected with the sculptural images of A. Pavlova in the role of The Dying Swan was created by the same masters in the genre of ballet portrait. These are Anna Pavlova - The Swan (1930, foreign collection) by G. Lavrov and Anna Pavlova - The Swan by S. Sudbinina (State Central Theatre Museum named after $A$. Bakhrushin). The mentioned works are distinguished by the deep penetration of artists into the image of dance. Even though the artists fix the ballerina's head; nevertheless, in the portrait, they also solve the problem of expressing the movement. Both portraits are characterised by a strained bend of the head, where both dancer's face and neck are carefully depicted. It would be wrong to consider that in these images the sculptors solve only a problem of mechanical motion. The sense of movement lies not so much in the figurative motive as in the dramatism of plastic comparisons and feelings A. Pavlova - The Swan by S. Sudbinin, in their lyricism - A. Pavlova - The Swan by G. Lavrov. The comparison of the works of two masters shows that the artists interpret the same motives differently. S. Sudbinin has the opportunity to partially monumentalise an image of A. Pavlova, strives for the maximum concentration of the image, while G. Lavrov is a gifted lyric poet, he adds fine poetry to the same motive and partly idealises it. Fine calm modelling of the face and its lyrical 
interpretation have much in common with $\mathrm{O}$. Rodin's images made in marble: Kiss, Everlasting Spring, and other works with the radiant surface permeated with light, where techniques of the contrast of the worked and unworked stone are used. The image of the ballerina tends to $\mathrm{O}$. Rodin's images not only stylistically, but also in the expression of subtle nuances of human emotions. It attracts by the state of dreaminess, careful listening, and the combination of fragile grace and spiritual movement. Working on A. Pavlova's image in Paris, on the business trip of the People's Commissariat of Education, G. Lavrov improved his sculpture skills from prominent French masters. A. Pavlova - The Swan by G. Lavrov represents the life during the dance, while "A. Pavlova - The Swan by S. Sudbinin is the embodiment of the mental torment of the last dying moments of the Swan. S. Sudbinin gives only the very essence of the role, as a certain ultimate concentrate, a clot of feeling, psychological agitation passing into calmness, harmonious clarity. Noting the opposition of the images created by G. Lavrov and $S$. Sudbinin, a single ideological and philosophical concept can be seen in them-A. Pavlova's romantic roles embodied in the unforgettable choreographic miniature.

\section{The Author's Concept of The Dying Swan in A. Pavlova's Sculpture}

A. Pavlova mainly refers to sculpture, as if she understands that she has special, truly limitless possibilities in the reproduction of plastic ballet. Choreography based on movement is always connected with the spatial orientation of volume. It can only be reproduced within sculptural art that allows creating an impression of both flexible and directly three-dimensional pattern of a dance. The sculpture is volumetric as a ballet performance for us. Pavlova's closest person, her husband and an impresario said the following about this part of the ballerina's activity: "Anna Pavlova always had a particular affection for sculpture. During each trip to Paris, she visited the Rodin Museum and all the exhibitions. The constant study of movements of the human body and its lines developed her comprehension of sculpture and critical sensitivity to its creators. Clusel was the first sculptor she got acquainted with many years ago" (Dandre, 2003: 592).

Another illustrative example is Pavlova's friendship with the Russian sculptor G. Lavrov, who captured Pavlova in many of his sculptural works (they have already been a subject of our study). They worked together in the art studio, when A. Pavlova told Lavrov the nuances of correct ballet movements and poses, and, while observing the sculptor's work, he taught her the tricks of plastic art. We can suppose that one of the best well-known sculptures of $A$. Pavlova $-A$. Pavlova - The Dying Swan (foreign collection) reproduced in Sotheby's catalogue of 1956 (Pavlova, 1956) - contrasts with the rest sculptures both by its peculiar spatialcompositional and figurative solution. It is an important complementary step in the way of creation of the same-name stage image. In this sculptural work made in bronze, the dancer does not focus her attention on the beauty of the swan costume, but primarily reproduces the essence of the image, the formula of in-depth and expressive movement. Unlike the sculptors, who captured A. Pavlova acting in this performance, she sets her purely professional tasks, solves the problem of the swan's flight system: how will it look on the ground, how does the bird turn the rectilinear position into the curvilinear one when stopping its movement, how does the body axis change, is the bending of the hands necessary at the ends of the wings? "Studying the world of the animal through man's movement in sculpture, searching for the rational position of the pose necessary for a ballet image, Pavlova not only wants to achieve beautiful plasticity and express both the spiritual life of the image and a flexible body as a property making up the main and integral part of the manbird, she considers her image in The Dying Swan as a completely autonomous system closed in itself" (Portnova, 2015). Pavlova even bought swans to copy their movements for her dance. "In 1913, Saint-Saëns, an author of the music for the ballet The Dying Swan visited her." He saw Pavlova on stage in the role of the swan and came to show respect to her. Pavlova took her 
guest to the park on the pond, and showed him her favourite swan Jack.

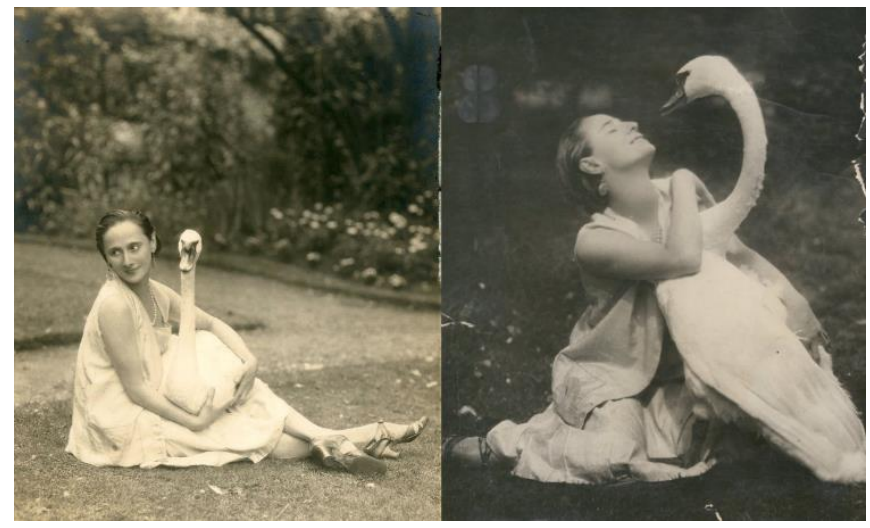

Figure 5: A. Pavlova with her Favourite Swan, Jack. In the garden of the Ivy House Manor in the Hampstead area. Source: Lafayette from a Private Collection, London.

It was touching to see the swan hugging its mistress by the neck (Antonov, 1966). "In 1927, Victor Dandre specially invited a famous British photographer James Lafayette to Anna Pavlovna's house for a photo shoot with Jack. These amazing pictures later became wellknown ..." (Shergalin, 2014: 248). Observations of the peculiarities of the bird's behaviour and movements helped the ballerina to create a creature living in accordance with its natural laws, to see an image from some other world. The birth of A. Pavlova's new choreographic performance is accompanied by a special way of thought that is peculiar only to her. Despite the fact that this dance, specially staged by $M$. Fokine for A. Pavlova, which later became a world triumph for the ballerina, amazed by its power of deep spirituality, when each barely perceptible detail, movement and rhythm depicted the inner state of tragedy. The composer A. Tcherepnin noted the following: "This slow movement of the hands taking away the entire essence of the dancer seems to be endless. As if it expresses the last plea. Plea for what?! As the desperate obedience. To whom?! Then again this 'crouch,' the last one is lower, the ballerina's figure is also lower, she lies on the stage floor like a white pile, immoveable and dead, with a head resting on her shoulder. Chord harp, violin harmonic tone. All this is The Dying Swan by Anna Pavlova" (Cherepnin, 1914). This short, but deeply emotional performance, which seems to provoke intense manifestations of feelings in the author, is restrained here by the framework of a rather strict task. Having selected the final of the dance for the plot of the sculpture, Pavlova was sure and convinced of the accuracy of her choice and the correctness of the solution found. As stated above, her scientific interests were solely the main impetus to the creation of the image. Here, A. Pavlova acts more as a ballerina, not as an artist. The texture of the material is of unworked bronze, not hidden, not likened to the model, but, on the contrary, specially unfinished, it is one more proof of the sketchiness of the work on this artwork. Not just an interest in the description of the movement, but in the peculiar analysis of this movement can be observed here. These qualities bring together A. Pavlova and E. Degas, in whose art a cognitive aspect is so exceptionally apparent. However, this is a strength of choreographers engaged in fine arts, in comparison with professional artists working on the ballet theme, since due to their ballet unpreparedness, the lack of knowledge of all the features of the dancer's life, even having certain experience and frequent observation, sometimes they cannot express a dance in the way ballet dancers and choreographers can do it. It is no wonder that, when working with a sculptor G. Lavrov, A. Pavlova helped him with professional advice. This does not mean that we cast doubt on the artistic level of absolutely all 
the works of professional artists engaged in the ballet theme. E. Degas was not a ballet dancer, but, when depicting the ballet, he managed to capture the entire professional distinctness of poses, which allowed him to see the body in a new way and learn many movements that none of artists had been interested in before him. Speaking of the undoubted merits of ballet dancers - artists, one cannot ignore their specific contradictions and weaknesses that are just as natural. Thus, A. Pavlova seeks to study the scheme of the bird's movement in the sculpture The Dying Swan to some extent to the detriment of the spiritual origin, when an interest in the anatomy of a dance, the level of joint mobility, muscle work plays a major role. It seems that the ballerina sets an experiment, thinks in its terms, studies up the methodology, goes from the simple to the complex, from the fact observation to the generalisation. She skillfully and professionally conducts her creative research, as if she discloses "work secrets" before us, introduces us to her creative laboratory. The sculptural version became for A. Pavlova the vivid development of the image of The Dying Swan created on stage.

\section{Discussion}

The analysis of the nature of the artistic imagery of the choreographic image of the swan imprinted in still images is of great importance for the deeper understanding of the director's staging processes and the problems of artistic reflection of reality and the specifics of perception of visual art. Research results can be useful in the development of special courses, lectures and seminars on the theory of aesthetics, on the problems of specifics of art forms and an artistic image. The practical significance of the article is also in the possibility of including the research results in the historicaltheoretical concept of Russian choreographic culture. The materials of the analysis can be used in the development of textbooks, lecture courses in art criticism, culturology, ballet master art, choreographic drama, and choreographic composition methodology, etc. Some aspects of the work of artists and sculptors on the image of the swan played by A. Pavlova may also be interesting from a choreographic point of view both for directors and ballet dancers.

The practical importance of this research is of a wide theoretical and methodological nature and can be expressed in its use in the process of art and cultural studies of the dance space of a miniature; a stage sphere visually depicted in paintings, as support material for a theatre designer (including a lighting designer); as methodological material for the aesthetic and theoretical understanding of the artistic process of the birth of a role in contemporary art; and as historiographic basis for further contemporary choreographic concepts.

\section{Conclusion}

As a result of the study, two types of iconography of the image of The Dying Swan performed by A. Pavlova can be revealed: performance of the work associated with the staging activity, i.e. the activity on the embodiment of the role on stage, which forms the staging of the act and the performance of the artwork, not directly connected with the staging activity, but indirectly, i.e. embodied in a similar, but still different form of plastic creativity. The image of the swan connected with the display of its performance will always be oriented to a director. The image of the swan, which is not related to the staging activity, can be created both by the author of the artwork and by a performer. Each artist, capturing A. Pavlova in the image of The Dying Swan, develops his own plan for displaying a depictive plot, i.e. revealing the nature of visual drama, which influences the iconography of the image. Visual drama is understood as the main theme, as well as the nature of its sounding determined by its intraformat artistic solution.

Classical dance is the most developed system of expressive dance, its plastic motives, including the image of the swan, never lose their inherent abstraction and associativity. As noted by $\mathrm{V}$. Dandre: "Pavlova's line is not only decorative or expressive. It is symbolic. Thus, we perceive the ballerina's arabesque as a certain visible sign of an unspeakable message. The technique of the classical dance school speaks the inspirational language of hieroglyphs here" (Dandre, 2003: 
592). The personal data of the ballet dancer participating in the choreographic performance of the act are an objective factor in creating the sustainable iconography of the image of the swan. "Pavlova's concept gave birth to the image of a beautiful human soul, which is destined to die in a collision with ordinary cruelty. It should be assumed that Pavlova's interpretation caused the appearance of the epithet 'dying'" (Smirnova, 2004). The uniqueness of the artistic image created by A. Pavlova is based on the uniqueness of objective data inherent in the performer by nature and developed by the school. The final pose of The Dying Swan actually underlies the composition of the overwhelming majority of the created artworks, the compositional and stylistic structure of these works does not always correspond but tends to an ideal "classical" form.

\section{References}

Antonov, V. (1966). In Memory of the Swan, Russian News.

Catalogue of the Commemorative Exhibition organized by the London Museum (1956). London, pp. 223.

Cherepnin, A. (1914). Ballet Symbols, Theater Newspaper, 35, pp. 8.

Cherepnin, A. (1914). Evening of Anna Pavlova, Theater Newspaper, 23, pp. 3.

Dandre, V. (2003). Anna Pavlova. Life and Legend. Moscow: Vita Nova, pp. 592.

Edward, M. (2018). Dying swans and dragged up dames. In Mesearch and the Performing Body (pp. 75-93). Palgrave Pivot, Cham.

Fisher, J. (2012). The Swan Brand: Reframing the Legacy of Anna Pavlova, Dance Research Journal, 44(1), pp. 51-67.

Fokine, M.M. (1961). The Dying Swan, Leningrad: Muzyka, pp. 32.

Fokine, M.M. (1981). Against the Current: Memoirs of the Ballet Master, Scenarios and Plans of Ballets, Articles, Interviews and Letters, Leningrad: Iskusstvo, pp. 510.

Granenbeiy, A. (1927). Anna Pavlova, pp. 172.

Grutsynova, A.P. (2012). "The Dying Swan" between Ballet and Cinema, Contemporary Science and Education Almanac, 8, pp. 35-38.
Hyden, W. (1932). La Pavlova, Paris, pp. 209.

Kerensky, O. (1973). Anna Pavlova, London, pp. 160.

Kranss, E. (1931). Anna Pavlova, Hear leven en haar Kunst, Amsterdam, pp. 239.

Materials about A. Pavlova. Catalog of the Exhibition, Concert Program Dedicated to Her Memory (in French), Russian State Archive of Literature and Art, File 2586, Inv. 1, Archival Unit 81

McLean, A. L. (2008). Dying swans and madmen: Ballet, the body, and narrative cinema, Rutgers University Press.

Money, K. (1982). Anna Pavlova: Her Life and Art, New York, pp. 425.

Nadezhdin, N.Ya. (2010). Anna Pavlova: From the Life of Swans, Moscow: Major; Osipenko, pp. 192.

Neishtadt, V.I. (1950). Extracts from Articles and Reviews about A. Pavlova's Creativity Made to Work on the Study of the Ballet History, Russian State Archive of Literature and Art, File 1525, Inv. 1, Archival Unit 242.

Pavlova, A. (1882-1931). Catalogue of the Commemorative Exhibition Organized by the London Museum. (1956). London, pp. 27.

Portnova, T.V. (2015). The Role of the Artistic Works of Anna Pavlova in the Creation of Scenic Images, Russian Humanitarian Journal, 4(4), pp. 282-289.

Shergalin, E.E. (2014). Swans and Other Birds in the Life of Great Anna Pavlova (1881-1931), Russian Ornithological Magazine, 23(961), pp. 247-252.

Smirnova, V.N. (2004). Artistic Alter Ego of Anna Pavlova (Ph.D. Thesis Abstract), Saransk, pp. 17.

Smirnova, V.N. and T.A. Kozina (2011). Interpretation of A. Pavlova's Art in the Historical-Cultural Context of the "Silver Age", News of Penza State Pedagogical University named after V.G. Belinsky, 23, pp. 245-251.

Sobolev, Yu. (1914). Forever Feminine, Ramp and Life, 23, pp. 9-10. 